\title{
METÁFORA NA ESCOLA BRASILEIRA: DICIONÁRIOS EM PAUTA
}

\author{
A. Ariadne Domingues Almeida (UFBA)
}

\begin{abstract}
RESUMO: No espaço escolar brasileiro, de um modo geral, ainda, se trabalham as metáforas, de forma a apresentá-las aos alunos como um recurso retórico, limitado-as à língua, ao seu léxico e ao texto literário, ainda que, pelo menos desde os primórdios dos anos de 1980, com a publicação do livro Metaphors We Live By, de George Lakoff e de Mark Johnson, o fenômeno metafórico tenha sido direcionado ao pensamento, à ação, passando a ser interpretado como um mecanismo de compreensão do mundo que circunda os seres humanos, tendo sido, portanto, reinterpretado como uma ferramenta de conceptualização, logo, interconectado à cognição humana. Sabendo disso, elaborei um estudo cujo objetivo principal foi procurar compreender como a metáfora é apresentada em dicionários utilizados em escolas brasileiras, a fim de verificar se, nessas obras, já ocorre algum tipo de transposição didática que atualize as paráfrases definitórias. Após realização deste estudo, este artigo apresenta os seus resultados.
\end{abstract}

PALAVRAS-CHAVE: Metáfora; Ensino; Dicionários Escolares; Linguística Cognitiva; Metalexicografia.

\section{METAPHOR IN BRAZILIAN SCHOOL: DICTIONARIES IN DISCUSSION}

\begin{abstract}
In the Brazilian school environment, in general, even if work metaphors in order to present them to students as a rhetorical device, limited them to the language, its lexicon and literary texts, although at least since the early 1980s, with the publication of the book Metaphors We Live By by George Lakoff and Mark Johnson, the metaphorical phenomenon has been directed to thought, to action, but should be interpreted as a world understanding mechanism that encircles humans, having thus been reinterpreted as a conceptualization tool thus interconnected to human cognition. Knowing this, I prepared a study whose main objective was to try to understand how the metaphor is presented in dictionaries used in Brazilian schools in order to determine whether, in these works, as is some sort of didactic transposition to update the definitórias paraphrases. After this study, this paper presents the results.

KEYWORDS: Metaphor; Education; School dictionaries; Cognitive Linguistics; Metalexicografia.
\end{abstract}

\section{DIANTE DE UM INÍCIO: AS LINHAS NORTEADORAS DO ESTUDO}

O artigo, ora principiado, expõe resultados de um estudo que objetivou compreender como ocorre a abordagem da metáfora em dicionários utilizados em escolas brasileiras, especificamente, em obras lexicográficas destinadas a alunas e alunos do $6^{\circ}$ ao $9^{\circ}$ anos do Ensino Fundamental, aprovadas pelo Programa Nacional do Livro Didático — Dicionários, $2012^{1}$

1 Como é sabido, “o Programa Nacional do Livro Didático (PNLD) é o mais antigo dos programas voltados à distribuição de obras didáticas aos estudantes da rede pública de ensino brasileira [...] O PNLD é voltado para o ensino fundamental público, incluindo as classes de alfabetização infantil [...]”. Disponível em: www. 
(doravante, PNLD - Dicionários, 2012). Assim sendo, procurei verificar se, nessas obras, já ocorre algum tipo de transposição didática, de modo que apresentassem, em seus respectivos verbetes, paráfrases definitórias atualizadas que considerassem as atuais e recentes discussões acerca da metáfora promovidas no âmbito da Linguística Cognitiva ${ }^{2}$, por especialistas desse fenômeno, como George Lakoff, Mark Johnson (1999; 2002 [1980]) e Zoltán Kövecses (2005, 2009). Para atingir aos objetivos estabelecidos, além de guiar-me por pressupostos da Teoria da Metáfora Conceptual (doravante, TMC), traçando diálogos com os autores antes citados, norteei-me por premissas da Metalexicografia, trazendo para as discussões pesquisadores como Sanromán (2000), Welker (2007) e Gomes (2007).

Com a finalidade de divulgar, no espaço acadêmico, o estudo desenvolvido e, em particular, os seus resultados, este artigo foi constituído por cinco partes que se interconectam, a fim de alcançar tal propósito, de modo que, para além da sua apresentação intitulada Diante de um início: as linhas norteadoras do estudo, o texto contém, também, as seguintes divisões: 1) Diante da metáfora: concepções tradicionais e concepções recentes, em que são apontadas e comentadas divergências entre duas relevantes linhas teóricas que se dedicam ao fenômeno metafórico; 2) Diante do ensino e dos dicionários: Metalexicografia e Metalexicografia Escolar, em que são expostos conceitos e objetivos dessas duas áreas do saber hominal; 2.1) Diante dos dicionários escolares e do PNLD: tipologia, em que são tecidos comentários, acerca da forma como dicionários escolares foram abordados no âmbito desse Programa, em sua última edição; 2.2) Diante dos dicionários escolares aprovados pelo PNLD-Dicionários, 2012, em que são indicadas as obras aprovadas pelo processo seletivo desse mesmo Programa; 3) Diante da metodologia: percursos do estudo, em que são traçadas as linhas metodológicas que conduziram o desenvolvimento da pesquisa realizada; 4) Diante da metáfora nos dicionários: um exercício para chegar a um entendimento do objeto de estudo, em que é exposto o percurso realizado, visando à compreensão do objeto em destaque, e são aduzidos os resultados alcançados; 5) Diante de um fim e de caminhos para um recomeço, em que são listadas as con-

http://portal.mec.gov.br/index.php?option=com_content\&view=article\&id=12391\&Itemid=668. Acesso em: 01.10.2010. Em 2000, foi “[...] inserida no PNLD a distribuição de dicionários da língua portuguesa para uso dos alunos de $1^{\mathrm{a}}$ a $4^{\mathrm{a}}[\ldots]$ " Disponível em: http://www.fnde.gov.br/index.php/pnld-historico. Acesso em: 01.10.2010.

2 A Linguística Cognitiva surge, entre os finais dos anos 70 e primórdios dos 80, como reação à visão puramente formalista da linguagem. Como ressalta Silva, "é uma abordagem da linguagem perspectivada como meio de conhecimento e em conexão com a experiência humana do mundo. As unidades e as estruturas da linguagem são estudadas, não como se fossem entidades autónomas, mas como manifestações de capacidades cognitivas gerais, da organização conceptual, de princípios de categorização, de mecanismos de processamento e da experiência cultural, social e individual" (SILVA, 1997, p. 59). 
siderações finais deste texto e outras vias de pesquisa, que, por sua parte, são seguidas pelas referências que alicerçaram as discussões constantes das linhas a seguir.

\section{DIANTE DA METÁFORA: CONCEPÇÕES TRADICIONAIS E CONCEPÇÕES RECENTES}

Como é sabido por quem se dedica à pesquisa sobre metáfora, no devir da constituição da tradição dos estudos retóricos, foi tomada como verdade uma série de postulados, a respeito desse fenômeno, de tal sorte que foi concebido e ratificado por eminentes pensadores que esse fenômeno se dava quando uma palavra fosse utilizada de forma distinta do seu uso cotidiano, do seu sentido próprio, natural, compreendendo-o, então, como uma questão léxica, por conseguinte, linguística, bem como foi entendido que a metáfora, apenas, ocorria, eventualmente, na língua, e que era característica, em especial, do texto literário, e, também, se pensava que a linguagem metafórica era corrompida, um desvio de usos naturais, originais, reais do léxico de uma língua e que os usos metafóricos convencionais do cotidiano eram metáforas já mortas, fixadas em expressões literais. Enfim, a metáfora era concebida como um mecanismo que evidenciaria similaridades preexistentes entre o que, normalmente, palavras designam e o que designam, quando são empregadas metaforicamente.

A partir dos finais dos anos 70, ocorreu, no seio da Linguística Cognitiva, uma releitura, ou melhor, uma reconceptualização do que se entendia por metáfora que, com o advento desse modelo científico, passou a ser vista como um modo de raciocinar sobre o mundo, através do qual os seres humanos são capazes criar realidades.

A metáfora, então, foi situada para além da linguagem; deixou de ser concebida, tão somente, como uma figura de linguagem e passou a ser lida como uma figura do pensamento, como um fenômeno humano conceptual, neural, corporal, linguístico, social e cultural (KÖVECSES, 2009), constituído historicamente.

Acha-se, portanto, a metáfora infiltrada no dia a dia de crianças, de mulheres e de homens, em seus pensamentos, em suas ações e não apenas em suas linguagens, visto que o sistema conceptual ordinário dos seres humanos é, em essência, metafórico (LAKOFF; JOHNSON (2002 [1980]), ainda que as suas diferentes linguagens, sendo todas concebidas metaforicamente como a ponta de um iceberg, possibilitem elaborar construções teóricas a- 
cerca do que acontece nas profundezas do cérebro, ou dito a partir outra perspectiva, o acesso a variadas redes de linguagem viabiliza pensar sobre as interconexões do ser humano com as suas experiências cotidianas, porque a conceptualização metafórica ou por qualquer outro mecanismo conceptual só acontece em interconexão interativa e integrativa; conclusão que elaborei, inspirada em minhas leituras sobre a Teoria da Complexidade (CAPRA, 2006; 2005; MATURANA; VARELA, 2001; MORIN $(2011 ; 2009)$ e sobre a própria Linguística Cognitiva (LAKOFF, 1996; 1999).

\section{DIANTE DO ENSINO E DOS DICIONÁRIOS: METALEXICOGRAFIA E METALEXICOGRAFIA ESCOLAR}

Assim como a Linguística Cognitiva, a Metalexicografia ou Lexicografia Teórica é uma área recente no Brasil, tendo sido os seus primeiros estudos confeccionados nos decênios derradeiros do século XX (WELKER, 2006). À Metalexicografia, cabe elaborar saberes teóricos e metodológicos a respeito dos produtos lexicográficos e as suas discussões mais profícuas tratam da tipologia de dicionários, da constituição histórica da lexicografia e da sua produção, da crítica aos produtos lexicográficos, dos usos feitos dos variados dicionários e, da mesma forma, das necessidades dos seus consulentes (SANROMÁN, 2000).

No devir do seu desenvolvimento, surgiu uma nova rede de pesquisa voltada, especificamente, ao ensino; trata-se, no caso, da Metalexicografia Escolar que consiste na "[...] análise teórica que visa fornecer subsídios conceituais e técnicos à lexicografia escolar [...]” (GOMES, 2007, p. 76). Assim sendo, essa nova rede do saber humano oferece contribuições teórico-metodológicas para a elaboração de materiais lexicográficos, empregados no plano educacional.

Os seus pesquisadores devem proceder ao estudo e à avaliação criteriosa de dicionários destinados ao público infanto-juvenil, de maneira tal que possam possibilitar que se reflita sobre essa produção dicionarística, bem como possam favorecer a geração de um posicionamento crítico dos agentes sociais da escola e, também, da família e, ainda, do Estado, em relação a um gênero textual ${ }^{3}$ tão importante para as sociedades com cultura escrita, uma vez que

3 Alguns consideram o dicionário como um suporte para o gênero verbete, Gonçalves (2012, p. 132), por exemplo, afirma que: “[...] faz-se necessário esclarecermos que o dicionário será considerado por nós como um suporte", para o gênero verbete. 
essa cultura, ao menos no Ocidente, ao longo de sua formação histórica, desejou, e, como consequência desse desejo, projetou, produziu e vendeu dicionários e continua a desejar, a projetar, a produzir e a vender dicionários. O mercado editorial desse segmento, ao menos, no que concerne ao espaço atinente aos dicionários escolares no Brasil, nunca esteve tão aquecido.

Os dicionários em geral e, consequentemente, os escolares possibilitam que se conheçam saberes formulados pelas pessoas com o adentrar dos anos, em diferentes espaços sociais, e, para uma comunidade acadêmica, ainda, bastante inspirada pelos ditames do cartesianismo, em que partes de um todo são segmentadas e analisadas, essas obras contemplam tanto os saberes formados pela cultura humanística, quanto científica, tanto saberes linguísticos quanto enciclopédicos, sendo que, de algum modo e paradoxalmente, valorizam e, ao mesmo tempo, diluem dicotomias tão apreciadas na ciência e tão bem avaliadas no cenário dos estudos linguísticos e em outras áreas do saber hominal ${ }^{4}$.

Por serem, então, os dicionários obras tão gerais de guarda da memória do conhecimento humano, de cariz histórico e, simultaneamente, normativo, prescritivo, conhecem, de um modo geral, apreciação e reconhecimento social e os conteúdos que apresentam, por um lado, acabam sendo lidos, relidos, ratificados, reproduzidos e, por outro, também, pelo próprio poder social que desfrutam, são comentados, avaliados, retificados ${ }^{5}$. Em face desse cenário multifacetado em que os dicionários se inscrevem nas sociedades que têm tradição escrita, pesquisadores da Metalexicografia procuram refletir sobre esses patrimônios dessa mesma cultura escrita, proporcionando o desenvolvimento, entre outros, de estudos críticos de variados dicionários, de tal modo que as reflexões sobre as obras lexicográficas voltadas para consulentes infanto-juvenis têm aumentado o seu escopo em diferentes espaços de poder, como o acadêmico, a partir da realização de pesquisas de Iniciação Científica, de Mestrado e de Doutorado, e como o do próprio Estado Brasileiro, a partir do desenvolvimento do PNLD - Dicionários.

4 Recentemente, desenvolvi um estudo em que discuto a perspectiva multidisciplinar e, ao mesmo tempo, interdisciplinar dos dicionários, pois, compreendo que se, por uma parte, conhecimentos de várias áreas são colocados, lado a lado, de maneira multidisciplinar, nos mais diferentes verbetes, por outro, a linguística é tomada, de uma forma interdisciplinar, pelo lexicógrafo e por sua equipe, visando à compreensão do léxico e de suas unidades constituintes em todos os seus aspectos.

5 Sobre as discussões que podem ocorrer na sociedade, a propósito do conteúdo apresentado em dicionários, conferir a polêmica, a respeito do verbete cigano, no dicionário Houaiss que apareceu, em diferentes veículos de circulação do domínio discursivo jornalístico, a exemplo da matéria Temporada de caça ao dicionário, de Luiz Costa Pereira Junior (2012). Disponível em: http://revistalingua.com.br/textos/78/temporada-de-cacaao-dicionario-255310-1.asp Acesso em: 10.12.2015. 
As reflexões desenvolvidas pelos pesquisadores em Metalexicografia Escolar são variadas, para exemplificar, no que concerne, especificamente, à microestrutura ${ }^{6}$ de obras usadas nas escolas, o que é, de certa forma, o objeto do estudo que ora apresento resultados, as pesquisas podem promover, por exemplo, discussões atinentes à inserção e à pertinência de definições, de exemplos e/ou de abonações; podem discutir se os dicionários trazem, em suas definições, preconceito social, o que ocorre não poucas vezes, inclusive, pela tensão do lexicógrafo em descrever e prescrever os usos das palavras (ALMEIDA, 2015).

\subsection{DIANTE DOS DICIONÁRIOS ESCOLARES E DO PNLD: TIPOLOGIA}

A mais recente edição do PNLD - Dicionários iniciou-se, em 2011, quando foi publicado o último Edital de convocação para o processo de inscrição e avaliação de dicionários brasileiros de língua portuguesa pelo referido Programa, adequados aos alunos dos Ensinos Fundamental e Médio da rede pública brasileira. Nesse Edital, são definidos quatro tipos de dicionários, tendo como público-alvo os alunos que se iniciam no processo de inserção no mundo da cultura escrita até aqueles que concluirão a última fase da educação básica, de forma que os diferentes dicionários foram divididos em quatro grupos, em consonância com as necessidades de cada fase escolar do Ensino Fundamental. O quadro a seguir, coletado do mencionado Edital, condensa as informações atinentes aos dicionários:

6 A microestrutura é o conjunto de informações oferecidas no artigo lexicográfico (PORTO DAPENA, 2002). Os informes dados nos verbetes podem variar, conforme os objetivos estabelecidos para o dicionário. Relativamente à microestrutura, Gomes (2007) apresenta os seguintes elementos constituintes da sua estrutura básica, além da entrada: 1) divisão silábica, 2) categoria gramatical, 3) definição, 4) exemplo e 5) plural. Também, observou que outros 24 itens eram optativos, de sorte que apareciam em certos verbetes, mas não em outros; os elementos facultativos, identificados pela referida autora, foram: 1) flexão verbal, 2) indicação de pronúncia, 3) indicação de prancha ilustrada, 4) nota gramatical, 5) gênero, 6) forma feminina, 7) forma masculina, 8) transitividade, 9) sílaba tônica, 10) palavra composta, 11) expressão idiomática, 12) locução, 13) colocação, 14) sinônimo, 15) antônimo, 16) remissão, 17) superlativo absoluto sintético, 18) paradigma de conjugação verbal, 19) marca de uso, 20) diminutivo, 21) aumentativo, 22) palavra derivada, 23) abonação e 24) informação enciclopédica. Gomes (2007) constatou que informes opcionais distribuíamse não equitativamente nos dicionários, pois a opção de inseri-los ou não liga-se à proposta lexicográfica, que, por seu turno, devia relacionar-se aos objetivos estabelecidos para cada ano de ensino, levando em consideração, ainda, a relação do seu público-alvo, tanto com o gênero dicionário/verbete, quanto com a escrita (ALMEIDA; GOMES, 2012). 
Quadro 1 - Informes sobre os dicionários consoante Edital de Convocação 01/2011 — CGPLIN

\begin{tabular}{|c|c|c|}
\hline Tipos de dicionários & Etapa de ensino & Caracterização \\
\hline Dicionários de tipo 1 & $\begin{array}{l}1^{\mathrm{o}} \text { ano do ensino fun- } \\
\text { damental }\end{array}$ & $\begin{array}{l}\text { - Mínimo de } 500 \text { e máximo de } \\
1.000 \text { verbetes; } \\
\text { - Proposta lexicográfica adequada } \\
\text { às demandas do processo de alfabe- } \\
\text { tização inicial. }\end{array}$ \\
\hline Dicionários de tipo 2 & $\begin{array}{l}2^{\circ} \text { ao } 5^{\circ} \text { ano do ensino } \\
\text { fundamental }\end{array}$ & $\begin{array}{l}\text { - Mínimo de } 3.000 \text { e máximo de } \\
15.000 \text { verbetes; } \\
\text { - Proposta lexicográfica adequada a } \\
\text { alunos em fase de consolidação do } \\
\text { domínio tanto da escrita quanto da } \\
\text { organização e da linguagem típicas } \\
\text { do gênero dicionário. }\end{array}$ \\
\hline Dicionários de tipo 3 & $\begin{array}{l}6^{\circ} \text { ao } 9^{\circ} \text { ano do ensino } \\
\text { fundamental }\end{array}$ & $\begin{array}{l}\text { - Mínimo de } 19.000 \text { e máximo de } \\
35.000 \text { verbetes; } \\
\text { - Proposta lexicográfica orientada } \\
\text { pelas características de um dicioná- } \\
\text { rio padrão de uso escolar, porém } \\
\text { adequada a alunos dos últimos anos } \\
\text { do ensino fundamental. }\end{array}$ \\
\hline Dicionários de tipo 4 & $\begin{array}{l}1^{\circ} \text { ao } 3^{\circ} \text { ano do ensino } \\
\text { médio }\end{array}$ & $\begin{array}{l}\text { - Mínimo de } 40.000 \text { e máximo de } \\
100.000 \text { verbetes; } \\
\text { - Proposta lexicográfica própria de } \\
\text { um dicionário padrão, porém ade- } \\
\text { quada às demandas escolares do } \\
\text { ensino médio, inclusive o profissio- } \\
\text { nalizante. }\end{array}$ \\
\hline
\end{tabular}

Fonte: file:///C:/Users/ada_d_000/Downloads/pnld_dicionarios_2012_edital.pdf

\subsection{DIANTE DOS DICIONÁRIOS ESCOLARES APROVADOS PELO PNLD- DICIONÁRIOS, 2012}

Após a fase de inscrição e, também, de realização de todo o processo de avaliação das obras inscritas no Edital de Convocação 01/2011 - CGPLI Programa Nacional do Livro Didático, PNLD — Dicionários 2012 — especificamente, no Edital de convocação para o pro- 
cesso de inscrição e avaliação de dicionários brasileiros de língua portuguesa para o Programa Nacional do Livro Didático - PNLD, foi divulgado o resultado do processo avaliativo, no Diário Oficial de 22 de março de 2012:

Figura 1 - Portaria n. 6, de 16.03.2012: divulgação do resultado da avaliação do PNLD — Dicionários, 2012

\section{SECRETARIA DE EDUCAÇÃO BÁSICA}

\section{PORTARIA № 6, DE 16 DE MARÇO DE 2012}

O SECRETÁRIO DE EDUCAÇÃO BÁSICA, no uso de suas atribuições, resolve:

Art. $1^{\circ}$ Divulgar o resultado da avaliação pedagógica das obras inscritas para o Programa Nacional do Livro Didático - PNLD Dicionários 2012, conforme o Edital de Convocação - 01/2011 CGPLI - para o processo de inscrição e avaliação de Dicionários Brasileiros de Língua Portuguesa para o Programa Nacional do Livro Didático - PNLD.

Art. $2^{\circ}$ As obras selecionadas, contidas na relação anexa a esta Portaria, serão distribuídas às escolas públicas federais e das redes de ensino municipais, estaduais e do Distrito Federal que ofereçam o ensino fundamental e o ensino médio. blicação. Art. $3^{\circ}$ Esta Portaria entra em vigor na data de sua pu-

\section{CFSAR C.AII.FGARI}

Fonte: file:///C:/Users/ada_d_000/Downloads/resultado_pnld_dicionarios_2012.pdf

Com essa divulgação, a sociedade tomou conhecimento das obras que foram aprovadas pelo PNLD - Dicionários, 2012, que foram, tão somente, cinco dicionários do tipo 3, conforme demonstra o quadro a seguir, também, coletado de outro maior, constante do referido Diário da União em sua seção 1:

Figura 2 - Extrato da Portaria n. 6, de 16.03.2012: resultado da avaliação do PNLD Dicionários, 2012, para tipo 3:

\begin{tabular}{|c|c|c|}
\hline & & resultado_pnld_dicionarios_2012.pdf \\
\hline \multicolumn{3}{|c|}{ Tipo 3} \\
\hline Código & Editora & Título da obra \\
\hline 32237L0000 & $\begin{array}{c}\text { EDITORA POSITIVO LT- } \\
\text { DA }\end{array}$ & $\begin{array}{l}\text { AURÉLIO JÚNIOR: DICIONÁRIO ESCO- } \\
\text { LAR DA LÍNGUA PORTUGUESA }\end{array}$ \\
\hline $32241 \mathrm{~L} 0000$ & $\begin{array}{l}\text { LEXIKON EDITORA DI- } \\
\text { GITAL LTDA }\end{array}$ & $\begin{array}{l}\text { CALDAS AULETE MINIDICIONÁRIO } \\
\text { CONTEMPORÂNEO DA LÍNGUA PORTU- } \\
\text { GUESA }\end{array}$ \\
\hline 32249L0000 & EDIÇOES SM LTDA & $\begin{array}{l}\text { DICIONÁRIO DIDÁTICO DE LÍNGUA } \\
\text { PORTUGUESA }\end{array}$ \\
\hline 32251L0000 & $\begin{array}{l}\text { COMPANHIA EDITORA } \\
\text { NACIONAL }\end{array}$ & $\begin{array}{c}\text { DICIONÁRIO ESCOLAR DA ACADEMIA } \\
\text { BRASILEIRA DE LETRAS - LÍNGUA } \\
\text { PORTUGUESA }\end{array}$ \\
\hline $32300 \mathrm{~L} 0000$ & $\begin{array}{c}\text { SARAIVA SA LIVREIROS } \\
\text { EDITORES }\end{array}$ & $\begin{array}{l}\text { SARAIVA JOVEM - DICIONÁRIO DA } \\
\text { LÍNGUA PORTUGUESA ILUSTRADO }\end{array}$ \\
\hline
\end{tabular}

Fonte: file:///C:/Users/ada_d_000/Downloads/resultado_pnld_dicionarios_2012.pdf 


\section{DIANTE DA METODOLOGIA: PERCURSOS DO ESTUDO}

Em face das diferentes etapas do ensino e dos variados dicionários voltados para o espaço escolar, conforme já pontuei, em outras passagens deste artigo, para proceder ao estudo, foram escolhidas as obras lexicográficas aprovadas pelo PNLD — Dicionários, 2012, destinadas a estudantes $6^{\circ}$ ao $9^{\circ}$ anos do Ensino Fundamental, portanto, do tipo 3, sendo que, nessas obras, foram, especificamente, selecionados os verbetes para entrada metáfora. O recorte, considerando, exclusivamente, os dicionários do tipo 3, foi feito, pelo fato de serem, de um modo geral, os estudos sobre o fenômeno em questão principiados nos últimos anos do Ensino Fundamental; essa decisão é avalizada, inclusive, pelo próprio texto do Edital do PNLD Dicionários, quando lá se afirma que: “[N]os dicionários de Tipo 3 [...] a terminologia específica das diferentes áreas disciplinares curriculares do segundo segmento do ensino fundamental deve fazer-se significativamente presente" (EDITAL, 2011, p. 17 — Grifos meus) ${ }^{7}$.

Delimitados o objeto de estudo e a fonte a partir da qual a pesquisa seria desenvolvida, foram, então, consultados os verbetes destinados para metáfora constantes dos cinco dicioná$\operatorname{rios}^{8}$ aprovados pelo PNLD - Dicionários, 2012, pois, adotando este comportamento, o estudo realizado enfocaria verbetes de obras lexicográficas que passaram pelo crivo de renomados especialistas do léxico da língua portuguesa, bem como seria o trabalho ancorado pela certeza de serem essas obras parte do acervo de escolas públicas de todo o país, uma vez que as obras selecionadas pelo PNLD - Dicionários são distribuídas em instituições educacionais públicas do Brasil.

Depois de feita a leitura de cada verbete em cada uma das obras selecionadas, foi constituído o corpus, a partir da digitação, em um arquivo do Word, de todos os verbetes antes lidos; posteriormente, foram estudadas as microestruturas, com enfoque nas definições expostas, nos

7 Os dicionários do tipo 4, também, poderiam ter sido considerados, porém, o estudo não foi ampliado, devido à limitação do tempo destinado à elaboração deste artigo e do espaço para a exposição dos resultados alcançados.

8 Ao longo da exposição deste estudo, alguns dicionários serão citados por meio de siglas, quais sejam: SM, para o Dicionário Didático de Língua Portuguesa, e ABL, para o Dicionário Escolar da Academia Brasileira de Letras - Língua Portuguesa, outros serão retomados, metonimicamente, pelo nome do organizador da obra em pauta, no caso do Aulete - Caldas Aulete Minidicionário Contemporâneo da Língua Portuguesa - e no do Ferreira - Aurélio Júnior: Dicionário Escolar da Língua Portuguesa, e outro, ainda, será recobrado pelo de nome de sua editora, especificamente, o Saraiva — Saraiva Jovem Dicionário da Língua Portuguesa Ilustrado. Assim sendo, não será feita a referenciação de uma dada obra toda vez que a mesma for citada, por isso, caso considere necessário, o leitor deverá verificar as referências completas ao final do texto. 
exemplos ou nas abonações e nas marcas de uso aduzidas em cada uma dessas obras, ainda que outras informações dadas em suas microestruturas não tenham sido desprezadas.

A fim de compreender os elementos constitutivos das microestruturas dos dicionários postos, aqui, em destaque, no tocante à entrada para metáfora, com base nas informações constantes dos próprios verbetes constituintes do corpus, foram estabelecidas oito categorias, visando ao desenvolvimento das reflexões sobre o objeto de estudo, quais sejam: 1) sílabas; 2) classe; 3) marcas de uso; 4) definição; 5) exemplo/abonação; 6) derivação; 7) étimo; 8) uso, ainda que o cerne deste estudo diga respeito, especialmente, a três dessas categorias, a saber: a) definição, b) exemplo/abonação e c) marcas de uso, dado que são essas as categorias que permitem saber como os dicionários escolares aprovados pelo PNLD - Dicionários, 2012 compreendem o uso e o conceito de metáfora.

\section{DIANTE DA METÁFORA NOS DICIONÁRIOS: UM EXERCÍCIO PARA CHEGAR A UM ENTENDIMENTO DO OBJETO DE ESTUDO}

Ao comentar para que serve um dicionário, Rangel (2012) enfoca a questão da terminologia no dia a dia de uma sociedade, de modo a tratar da importância dos saberes acerca das palavras terminológicas, para os utentes de uma língua, pois esses saberes podem ser cruciais para a infalibilidade de determinada situação cotidiana, quer quando as pessoas usam a oralidade, quer a escrita.

A fim de exemplificar a sua discussão, o autor traz como exemplo o domínio discursivo da medicina e comenta a necessidade de um médico conhecer, em relação à terminologia que usa, em interação com o paciente, o significado e as distinções efetivas entre os termos da sua área e os vocábulos empregados, corriqueiramente, pela população não especializada, pois acredita que, apenas, dessa maneira, o médico poderá se assegurar que o paciente compreendeu o diagnóstico e, assim, o último prosseguirá com o seu tratamento.

Ainda, afirma que, por explicar e por fazer circular a terminologia da área, o médico poderá ouvir do paciente uma descrição mais eficiente acerca da sua saúde, de sorte que acabará se favorecendo com isto, já que, conforme pensa Rangel (2012), traduzir a terminologia que utiliza e fazer a transposição da linguagem do paciente para a da medicina, no momento 
de fazer o diagnóstico, não é, tão somente, uma questão de educação ou de habilidade pessoal/social do médico, mas parte inerente do seu trabalho.

Em sequência, de um lado, Rangel (2012) destaca que todo e qualquer especialista, quando informa ou relata sobre os seus atos a quem é de direito, acaba se colocando em face dessa mesma necessidade e, de outro, esse autor salienta que os dicionários são obras que auxiliam os seus consulentes nessas situações, de tal maneira que reduzem o espaço entre o vocabulário, os recursos lexicais que o usuário possui e as possibilidades de que o léxico dispõe, logo, sempre que o sentido de uma palavra estiver em foco, os dicionários poderão colaborar sobremaneira com aquele que os consulta.

Não indo tão longe quanto Rangel (2012) e, também, não saindo da esfera do domínio discursivo da educação, acredito que a terminologia empregada em textos didáticos, a partir da segundo ciclo do Ensino Fundamental, precisa ser compreendida por professores e, também, por alunos, e, se o dicionário tem a função de apresentar essa terminologia, como já ressaltou Rangel (2012), precisa fazer isto com qualidade, pois, ainda, como destaca o mesmo autor:

\begin{abstract}
Os dicionários de Tipo 3 devem cobrir um conjunto mais diverso e mais complexo de lexias, estendendo a experiência do aluno para todos os tipos de palavras (lexicais e gramaticais; simples e compostas; expressões idiomáticas; neologismos; palavras de uso restrito; etc.), e para um maior número de esferas públicas da comunicação, com destaque para a mídia e as produções escritas destinadas ao público infantojuvenil, como os cadernos ou seções próprias para crianças e jovens (em revistas e jornais de grande circulação), a literatura infanto-juvenil e os materiais didáticos voltados para o ensino fundamental. A terminologia específica das diferentes áreas disciplinares curriculares do segundo segmento do ensino fundamental deve fazerse significativamente presente (RANGEL, 2012, p. 94; Grifos meus).
\end{abstract}

Diante da importância da terminologia para a sociedade em geral e para a educação, especificamente, penso ser necessário, então, proceder a questionamentos em relação ao comportamento dos dicionários voltados para a educação básica, de tal maneira que, no âmbito deste estudo, cabe-me perguntar se essas obras da lexicografia estão, de fato, tratando a terminologia com a devida qualidade, bem como cabe-me indagar se estão definindo os termos usados nos livros didáticos e, no caso específico do objeto de estudo aqui posto em tela, cabeme perguntar se tratam a metáfora e, se sim, como é feita esta abordagem. 
Hoje, cada vez mais, é defendido que os alunos não precisam ter um conhecimento arraigado de metalinguagem ${ }^{9}$, mas a tradição metalinguística do ensino de língua portuguesa, ainda, não deixou de ter forte influência nos espaços escolares e de propagar metalinguagem sem uma maior reflexão, sem pensar criticamente sobre essa metalinguagem e, pelo que sei, de um modo geral, salvo poucas exceções, não se produz, ainda, um ensino epilinguístico eficiente e com a qualidade esperada em todas as escolas brasileiras, especialmente, quando o público-alvo dessas escolas é constituído de alunos oriundos das classes sociais menos favorecidas da sociedade. Dessa maneira, é preciso refletir como os dicionários, instrumentos utilizados para a realização de leitura e escrita de qualidade, amplamente, difundidos nas sociedades com cultura escrita e, assim sendo, também, propagados no Brasil, tratam os fenômenos semânticos e, em particular, a metáfora.

Postas estas primeiras observações, passo a exposição do estudo propriamente dito. Inicialmente, apresento o quadro a seguir em que são colocadas, paralelamente, as informações obtidas nos verbetes para metáfora dos cinco dicionários consultados:

9 Conforme Antunes (2007), por exemplo, não há necessidade de apressar e trazer para as primeiras séries a estranheza da metalinguagem, com definições, classificações e subdivisões. 
Pontos de Interrogação, v. 5, n. 1, jan./jul. 2015

Revista do Programa de Pós-Graduação em Crítica Cultural Universidade do Estado da Bahia (UNEB), Campus II - Alagoinhas - BA

\section{Quadro 1 - Os dicionários e as categorias estabelecidas para o estudo}

\begin{tabular}{|c|c|c|c|c|c|c|c|c|}
\hline Dicionário & $\begin{array}{l}\text { Separação de } \\
\text { sílabas }\end{array}$ & Classe & $\begin{array}{l}\text { Marcas } \\
\text { de uso }\end{array}$ & Definição & $\begin{array}{l}\text { Exemplo/ } \\
\text { Abonação }\end{array}$ & Derivação & Étimo & Uso \\
\hline $\begin{array}{l}\text { AULETE } \\
(2012)\end{array}$ & (me.tá.fo.ra) & sf. & Gram. & $\begin{array}{l}\text { Figura de linguagem } \\
\text { que consiste em } \\
\text { estabelecer uma } \\
\text { analogia de signifi- } \\
\text { cados entre duas } \\
\text { palavras ou expres- } \\
\text { sões, empregando } \\
\text { uma pela outra. }\end{array}$ & $\begin{array}{l}\text { (p. ex. asas da } \\
\text { imaginação). }\end{array}$ & me.ta.fó.ri.co a & $\begin{array}{l}\text { [F.: Do lat. } \\
\text { metaphora, } \\
\text { ae] }\end{array}$ & \\
\hline $\begin{array}{l}\text { SARAIVA } \\
(2010)\end{array}$ & me.tá.fo.ra & sf. & Ling. & $\begin{array}{l}\text { Figura de linguagem } \\
\text { que consiste em } \\
\text { utilizar uma palavra } \\
\text { em lugar de outra } \\
\text { por haver entre elas } \\
\text { uma relação de } \\
\text { semelhança. }\end{array}$ & $\begin{array}{l}\text { (quando se diz } \\
\text { que alguém tem } \\
\text { um "coração de } \\
\text { pedra", usar o } \\
\text { significado de } \\
\text { "pedra" para } \\
\text { exprimir dureza e } \\
\text { falta de sentimen- } \\
\text { tos é uma metáfo- } \\
\text { ra.) }\end{array}$ & & & \\
\hline $\begin{array}{l}\text { FERREIRA } \\
(2011)\end{array}$ & me.tá.fo.ra & $\begin{array}{l}\text { subst. } \\
\text { fe }\end{array}$ & $\begin{array}{l}\text { Lingua- } \\
\text { gem }\end{array}$ & $\begin{array}{l}\text { Recurso da lingua- } \\
\text { gem em que a signi- } \\
\text { ficação natural duma } \\
\text { palavra é substituída } \\
\text { por outra com que } \\
\text { tem relação de se- } \\
\text { melhança. }\end{array}$ & $\begin{array}{l}\text { [Por metáfora, } \\
\text { chama-se raposa a } \\
\text { uma pessoa astu- } \\
\text { ta] }\end{array}$ & & & \\
\hline $\begin{array}{l}\text { SM } \\
(2009)\end{array}$ & (me.tá.fo.ra) & sf. & & $\begin{array}{l}\text { Figura de linguagem } \\
\text { em que se designa } \\
\text { um ser por outro } \\
\text { nome, para indicar } \\
\text { uma qualidade que } \\
\text { não aparece, mas } \\
\text { pode ser subenten- } \\
\text { dida. }\end{array}$ & $\begin{array}{l}\text { Ela é uma flor é } \\
\text { uma metáfora para } \\
\text { indicar uma pes- } \\
\text { soa delicada ou } \\
\text { bonita. }\end{array}$ & & & $\begin{array}{l}\text { [] uso É } \\
\text { diferente } \\
\text { de com- } \\
\text { paração } \\
\text { *figura } \\
\text { de lin- } \\
\text { guagem } \\
\text { em que } \\
\text { se estabe- } \\
\text { lece } \\
\text { expres- } \\
\text { samente } \\
\text { um seme- } \\
\text { lhança } \\
\text { em dois } \\
\text { ou mais } \\
\text { termos) }\end{array}$ \\
\hline $\begin{array}{l}\text { (ABL, } \\
2008)\end{array}$ & (me.tá.fo.ra) & s.f. & (Gram.) & $\begin{array}{l}\text { Figura de linguagem } \\
\text { que consiste em } \\
\text { designar uma coisa, } \\
\text { mediante uma pala- } \\
\text { vra cujo significado } \\
\text { tem uma relação de } \\
\text { semelhança ou } \\
\text { analogia. }\end{array}$ & $\begin{array}{l}\text { "A vida é um } \\
\text { barco a voar" é } \\
\text { uma bela metáfora } \\
\text { do poeta Alphon- } \\
\text { so Guimarães. }\end{array}$ & metafórico adj. & & \\
\hline
\end{tabular}

Fonte: Própria autora 
As informações constantes dos verbetes estudados são: 1) separação de sílabas, 2) classe de palavras, 3) marcas de uso, 4) definição; 5) exemplo/abonação; 6) derivação, 7) étimo e 8) uso, por isto mesmo, essas foram as categorias propostas para nortear as reflexões, aqui, promovidas. Alguns desses conteúdos figuram em todos os verbetes, mas outros não. A primeira, segunda, quarta e quinta categorias (separação de sílabas, classe de palavras, definição e exemplo/abonação) documentam-se em todas as microestruturas destinadas à entrada metáfora dos dicionários consultados, já a terceira (marcas de uso) falta no SM, enquanto a sexta (derivação) registra-se, tão somente, no Aulete e no ABL; a sétima (étimo), por sua vez, aparece, apenas, nesse primeiro, ou seja, no Aulete, e, finalmente, a oitava (uso), no SM. Assim sendo, o conteúdo que constitui a parte estrutural dos verbetes é variável.

De todas as categorias antes arroladas, considero, de um lado, a primeira, a segunda, a sexta e a sétima (separação de sílabas, classe de palavras, derivação e étimo) acessórias, no âmbito deste estudo, e, por outro, tomo a terceira, a oitava e, sobretudo, a quarta e a quinta categorias (marcas de uso, uso, definição e exemplo/abonação) como basilares para o entendimento de como os dicionários aprovados pelo PNLD — Dicionários, 2012 compreendem a metáfora e, também, para saber se essas obras apresentam algum tipo de transposição didática dos mais recentes conhecimentos adquiridos pela TMC.

No que concerne aos informes, aqui, considerados secundários (separação de sílabas, classe, derivação e étimo), os cinco dicionários oferecem informações idênticas, a respeito da separação de sílabas e da classe de palavras, o que, obviamente, demonstra que essas obras seguem a norma culta do português do Brasil; no entanto, no tocante à derivação, apenas, o Aulete e o ABL informam-na, de tal modo que dão a conhecer a formação adjetival (metafórico, a), no mesmo verbete para metáfora, enquanto outros trazem-na em outra microestrutura específica para o adjetivo. Esse comportamento variável se justifica pelos critérios de estabelecimento da macroestrutura de cada obra. Essa variação expressa, da mesma forma, que não há uniformidade, no tocante à abordagem dada ao léxico nos diferentes dicionários. Relativamente ao étimo, apenas, é informada a origem da palavra pelo Aulete, dado que nenhum outro traz a etimologia da entrada metáfora. Inclusive, devo pontuar que esse informe constante deste verbete desse dicionário pode ser discutido, uma vez que é atribuída uma origem latina sem qualquer menção ao grego que, em última instância, pode ser considerado seu étimo remoto.

No tocante às categorias fulcrais do estudo, relativamente, à terceira categoria, marcas de uso, foram identificadas diferenças entre os dicionários, pois, se, por uma parte, o Aulete e 
o ABL inserem, em seus respectivos verbetes, a marca de uso gram., colocando a metáfora no âmbito da gramática, por outra, o Saraiva e o Ferreira projetam-na para domínio de uso da linguagem. Além disso, o SM não oferece informes acerca dessa categoria. A respeito do uso, oitava categoria, aqui, examinada, o dicionário $\mathrm{SN}$, único a inseri-la, procede à clássica dicotomia entre metáfora e comparação, entendendo a primeira com base em semelhanças subentendidas e a segunda como semelhanças expressas, sendo que essa dualidade não condiz com as premissas da Linguística Cognitiva que procura vencer visões dicotômicas tão preconizadas nos estudos linguísticos.

Sobre a quarta categoria — definição —, os cinco dicionários situam o fenômeno metafórico no plano da linguagem, sendo que quatro - Aulete, Saraiva, SM e ABL — categorizam-no como figura e um — Ferreira - como recurso.

Também, é unânime a compreensão desse mesmo fenômeno como pertencente ao léxico das línguas (“[...] estabelecer uma analogia de significados entre duas palavras [...] (Aulete)"; “[...] utilizar uma palavra em lugar de outra [...] (Saraiva)”; “[...] significação natural duma palavra é substituída por outra [...] (Ferreira)”; “[...] designa um ser por outro nome [...] (SM)" e "[...] designar uma coisa, mediante uma palavra $[\ldots]$ " $\left.(\mathrm{ABL})^{10}\right)$, ainda que, no caso do SM, possa ser percebida uma concepção referencialista permeando o texto definitório e que, no Aulete, possa ser entrevista uma perspectiva para além das palavras, já que lá se compreende que a metáfora, também, se conecta com expressões.

Para além do subsistema léxico, o Aulete ("analogia de significados"), o Ferreira ("significação natural") e o ALB ("significado"11) evidenciam a relação semântica que ocorre na metáfora. No caso do Ferreira, chama a atenção o entendimento da metáfora como um tipo de desvio; afinal, é expresso, em seu verbete, que as palavras possuem significação natural que é substituída por outra; diante desta colocação, cumpre-me perguntar: o que seria mesmo uma significação natural de uma palavra?

A analogia é tida como mecanismo responsável pela metáfora ("estabelecer uma analogia de significados (Aulete)"; “designar uma coisa, mediante uma palavra cujo significado tem uma relação de semelhança ou analogia" (ABL)). Além disso, acredita-se que há uma relação de semelhança entre as palavras ("por haver entre elas [palavras] uma relação de $s e$ -

10 Todos os grifos registrados, neste parágrafo, são meus.

11 Também, neste parágrafo, os grifos são meus. 
melhança" (Saraiva); "significação natural duma palavra é substituída por outra com que tem relação de semelhança" (Ferreira); "designar uma coisa, mediante uma palavra cujo significado tem uma relação de semelhança ou analogia" (ABL) $)^{12}$.

No que diz respeito à categoria exemplo e/ou abonação, a maior parte dos casos é constituída por metáforas convencionais ("p. ex. asas da imaginação". (Aulete); "quando se diz que alguém tem um "coração de pedra". Usar o significado de "pedra" para exprimir dureza e falta de sentimentos é uma metáfora”. (Saraiva); “[Por metáfora, chama-se raposa a uma pessoa astuta]". (Ferreira); "Ela é uma flor é uma metáfora para indicar uma pessoa delicada ou bonita". (SM)). Apenas, o dicionário ABL, talvez, por ser um representante da Academia Brasileira de Letras, traz uma abonação coletada de um poeta (“A vida é um barco a voar" é uma bela metáfora do poeta Alphonso Guimarães”. (ABL)). Então, aqui, pode ser observada uma dissonância entre a tradição dos estudos retóricos, os quais limitam, basicamente, a metáfora ao campo da linguagem literária e os exemplos criados pela equipe lexicográfica, coletados, provavelmente, da própria memória de quem elaborou o verbete, de modo a indicar como usos metafóricos aqueles do cotidiano, com a exceção já mencionada do dicionário ABL. Assim sendo, há um nítido descompasso entre definições oferecidas e exemplos usados para ratificá-las, uma vez que os textos definitórios, principalmente, categorizam a metáfora como figura de linguagem.

\section{DIANTE DE UM FIM E DE CAMINHOS PARA UM RECOMEÇO}

Percebo, ainda meio intuitivamente, pois os estudos, aqui, propostos encontram-se em fase inicial de elaboração, que, no espaço escolar brasileiro, de um modo geral, se trabalham as metáforas, de forma a apresentá-las aos alunos como um recurso retórico, limitado-as à língua, ao seu léxico, mesmo tendo sido, pelo menos desde os primórdios dos anos 80, com a publicação do livro Metaphors We Live By, de George Lakoff e de Mark Johnson, o fenômeno metafórico direcionado ao pensamento, à ação, passando a ser interpretado como um mecanismo de compreensão do mundo que circunda os seres humanos, tendo sido, portanto, reinterpretado como um meio de conceptualização, logo, interconectado à cognição humana.

12 Neste parágrafo, todos os grifos que se documentam são meus. 
No Edital do PNLD — Dicionários, 2012, ao se tratar da qualidade das definições apresentadas nessas obras da Lexicografia, informa-se que "as definições apresentadas para os vocábulos devem estar livres de erros. [...]” (EDITAL, 2011, p. 18 - Grifos meus). Não posso afirmar que as definições estudadas expressam erro, no sentido de exporem o que já foi tido como verdade absoluta, no âmbito dos estudos sobre questões de significação, mas posso assegurar que são omitidas informações importantes acerca da palavra definida, pois outros conhecimentos já foram constituídos e são esses saberes mais atuais, completamente, silenciados.

Os resultados do estudo feito, a partir desse levantamento, demonstraram que não ocorre, nessas obras, a transposição didática de recentes conhecimentos elaborados pela TMC, embora sejam usados exemplos do cotidiano em boa parte dos verbetes esquadrinhados, e, ainda que, no Edital, se assegure que sobre a “[...] Contextualização[,] será observada a presença, para cada acepção, de exemplos ou abonações que auxiliem o aluno na compreensão dos empregos possíveis para dado vocábulo" (EDITAL, 2011, p. 18), não posso dizer que a contextualização oferecida nas obras ajudem, de fato, os alunos, porque não condizem, propriamente, com as definições apresentadas nas obras consultadas.

Enfim, apresentei, neste artigo que ora se finda, resultados parciais de uma pesquisa acerca do ensino da semântica que estou realizando, com membros do GESCOG — Grupo de Estudos em Semântica Cognitiva, associado ao PROHPOR — Programa para a História da Língua Portuguesa. E, embora este texto seja concluído agora, outros trabalhos serão realizados, de tal maneira que pretendo, em estudo vindouro, ainda, pesquisar os verbetes para metáforas em dicionários do tipo 4 , assim como almejo cotejar os diferentes verbetes, para saber se, de fato, há mudanças significativas nos verbetes dos dicionários dos tipos 3 e 4 . Pretendo, ademais, comparar os verbetes das obras aprovadas com as reprovadas e, ainda, com outras não escritas no Edital, para verificar se há mudanças significativas entre essas obras e tentar entender como ocorre a compreensão, no âmbito escolar, do que se entende por metáfora. E, ainda, almejo propor verbetes, para cada etapa do ensino, constituídos por informes que considero adequados para o que se entende por metáfora. 


\section{REFERÊNCIAS}

ALMEIDA, A. Ariadne D.; GOMES, Patrícia (2012). Lexicografia e ensino: em busca de um uso reflexivo do dicionário em sala de aula. Disponível em: http://media.wix.com/ugd/c8e334_38d04bbc102d4e26bb0a9884e7e3793d.pdf Acesso em 01.08.2015.

ALMEIDA, A. Ariadne D.; COELHO, Juliana Soledade Barbosa; GOMES, Patrícia Vieira Nunes (2008). Em busca da lexicografia didática: o uso do dicionário na sala de aula. In: MENDES, Edleise; CASTRO, Lúcia. (Org.). Saberes em português: ensino e formação docente. Campinas: Pontes. p. 187-203.

ALMEIDA, A. Ariadne D. O dicionário na escola brasileira: algumas questões ideológicas. In: ALMEIDA, A. Ariadne D.; ZOGHBI, Denise Maria Oliveira; SANTOS, Elisângela Santana dos. (Org.). Formação de professores e interconexões da sala de aula no ensino de línguas. Salvador: EDUFBA, 2015.

ANTUNES, Irandé Costa (2007). Muito além da gramática: por um ensino sem pedras no caminho. $1^{\text {a }}$ Edição. Belo Horizonte: Ed. Parábola.

AULETE, Caldas (2012). Dicionário escolar da língua portuguesa. Paulo Geiger (Org.). Rio de Janeiro: Lexicon.

BECHARA, Evanildo (Org.) (2011). Dicionário escolar da Academia Brasileira de Letras. 3. ed. São Paulo: Cia. Ed. Nacional.

CAPRA, Fritjof (1996). A teia da vida: uma nova compreensão científica dos sistemas vivos. Trad. Newton Roberval Eichemberg. São Paulo: Cultrix, 2006.

CAPRA, Fritjof (2002). As conexões ocultas: ciência para a vida sustentável. Trad. Marcelo Brandão Cipolla. São Paulo: Cultrix, 2005.

DIÁRIO OFICIAL DA UNIÃO. SEÇÃO 1, n. 57, quinta-feira, 22 de março de 2012. Disponível em: file:///C:/Users/ada_d_000/Downloads/resultado_pnld_dicionarios_2012.pdf. Acesso em 31.07.2015.

Dicionário didático. 3 ed. São Paulo: Edições SM, 2009:

Dicionário escolar da língua portuguesa/Academia Brasileira de Letras. 2 ed. São Paulo: Companhia Editora Nacional, 2008.

EDITAL DE CONVOCAÇÃO PARA O PROCESSO DE INSCRIÇÃO E AVALIAÇÃO DE DICIONÁRIOS BRASILEIROS DE LÍNGUA PORTUGUESA PARA O PROGRAMA NACIONAL DO LIVRO DIDÁTICO — PNLD. 2011. Disponível em: fi-

le://C:/Users/ada_d_000/Downloads/pnld_dicionarios_2012_edital.pdf. Acesso em:

31.07.2015.

FERREIRA, Aurélio Buarque de Holanda (2011). Aurélio Júnior: dicionário escolar da língua portuguesa. 2 ed. Curitiba: Positivo. 
FERREIRA, Aurélio Buarque de Holanda (2011). Aurélio Júnior: dicionário escolar da língua portuguesa coordenação de Mariba Baird Ferreira e Margarida dos Anjos, ilustrações Axel Sarde. 2 ed. Curitiba: Positivo.

GEIGER, Paulo (Org.) (2011). Caldas Aulete - minidicionário contemporâneo da língua portuguesa. 3 ed. Rio de Janeiro: Lexikon.

GOMES, Patrícia Vieira Nunes (2007). O processo de aquisição lexical na infância e a metalexicografia do dicionário escolar. Tese de Doutorado. Universidade de Brasília.

GONÇALVES, Sheila de Carvalho Pereira. (2012). A importância da análise de gêneros textuais na formação docente. Disponível em: file:///C:/Users/ada_d_000/Downloads/261-956-1PB.pdf Acesso em: 14.12.2015.

http://www.fnde.gov.br/programas/livro-didatico/livro-didatico-dados-estatisticos

LAKOFF, George (1987). Women, Fire, and Dangerous Things. What Categories Reveal about the Mind. Chicago: The University of Chicago Press.

LAKOFF, George; JOHNSON, Mark (1980). Metaphors We Live By. Chicago: The University of Chicago Press.

LAKOFF, George; JOHNSON, Mark. (1999). Philosophy in the Flesh. The Embodied Mind and its Challenge to Western Thought. Nueva York: Basic Books.

MATURANA, Humberto; VARELA, Francisco (1984). A árvore do conhecimento: as bases biológicas da compreensão humana. Trad. Humberto Mariotti e Lia Diskin. São Paulo: Palas Athena, 2001.

MORIN, Edgar (1999). Trad. Eloá Jacobina. A cabeça bem-feita: repensar a reforma, reformar o pensamento. Rio de Janeiro: Bertrand, 2009.

MORIN, Edgar (2005). Introdução ao pensamento complexo. 4 ed. Trad. Eliane Lisboa. Porto Alegre: Sulina, 2011.

PORTO DAPENA, José-Álvaro (2002). Manual de técnica lexicográfica. Madrid: Arco/Libros.

RAMOS, Rogério de Araújo (ed. resp.) (2011). Dicionário didático de língua portuguesa. 2 ed. São Paulo: SM, 2011.

RANGEL, Egon (2012). Com direito à palavra: dicionários em sala de aula/[elaboração Egon Rangel]. - Brasília : Ministério da Educação, Secretaria de Educação Básica. Disponível em: file://C:/Users/ada_d_000/Downloads/dicionario_em_sala_de_aula_pnld\%20(1).pdf. Acesso: 31.07.2015.

RANGEL, Egon; BAGNO, Marcos (2006). Dicionários em sala de aula. Brasília: MEC/SEB. Disponível em: http://portal.mec.gov.br/seb/arquivos/pdf/Avalmat/polleidicio.pdf. Acesso em: 01 feve. 2010.

SARAIVA JOVEM: dicionário da língua portuguesa ilustrado. Organização da editora. São Paulo: Saraiva. 2010. 
SARAIVA, Kandy S. de Almeida \& Oliveira, Rogério Carlos G. de (2010). Saraiva jovem; dicionário da língua portuguesa ilustrado. São Paulo: Saraiva.

SILVA, Augusto Soares da (1997). A linguística cognitiva. Uma breve introdução a um novo paradigma em linguística. Revista Portuguesa de Humanidades, 1/1-2, Braga: Faculdade de Filosofia da Universidade Católica de Braga, p. 59-101. Disponível em:

http://www.inf.unioeste.br/ jorge/MESTRADOS/LETRAS\%20-

$\% 20$ MECANISMOS\%20DO \%20FUNCIONAMENTO\%20DA\%20LINGUAGEM $\% 20$ -

\%20PROCESSAMENTO\%20DA\%20LINGUAGEM\%20NATURAL/ARTIGOS\%20INTER ESSANTES/Lingu\%EDstica\%20Cognitiva.pdf Acesso em 10.12.2015.

SILVA, Augusto Soares da. (1997). A linguística cognitiva uma breve introdução a um novo paradigma em linguística. Disponível em:

http://www.inf.unioeste.br/ jorge/MESTRADOS/LETRAS\%20-

$\% 20$ MECANISMOS\%20DO\%20FUNCIONAMENTO\%20DA\%20LINGUAGEM $\% 20$ -

$\% 20$ PROCESSAMENTO $\% 20$ DA\%20LINGUAGEM\%20NATURAL/ARTIGOS\%20INTER ESSANTES/Lingu\%EDstica\%20Cognitiva.pdf Acesso em: 14.12.14.

WELKER, H. A (2006). Breve histórico da metalexicografia no Brasil e dos dicionários gerais brasileiros. MATRAGA, Rio de Janeiro, ano 13, n.19, p. 69-84. Disponível em:

http://www.pgletras.uerj.br/matraga/matraga19/matraga19a04.pdf. Acesso em: 29.07.2015.

Recebido em 11 de março de 2015.

Aceito em 10 de maio de 2015. 